\title{
sciendo
}

\section{Corruption perceptions index and economic development of the country}

\author{
Liviu-Stelian BEGU \\ The Bucharest University of Economic Studies, Bucharest, Romania \\ liviu.begu@csie.ase.ro \\ Simona-Andreea APOSTU \\ The Bucharest University of Economic Studies, Bucharest, Romania \\ simona.apostu@csie.ase.ro \\ Andreea-Oana ENACHE \\ The Institute of National Economy \\ enacheoanaa@yahoo.com
}

\begin{abstract}
The phenomenon of corruption is known all over the world, and its intensity varies according to economic, behavioral and educational factors. Transparency International is a global civil society that carries out regular opinion surveys and publishes the perceptions of corruption in countries around the world. This index identifies the level of corruption perceived in the world and contributes achieving a ranking of countries in this regard. The corruption perception index should be correlated with economic situation of a country. The economic situation of a country can be reflected by GDP and unemployment rate. The purpose of this study is to determine whether the index of corruption is influenced by the economic situation of a country, so the study analyses the corruption perception index, GDP and unemployment rate, establishing whether there is a link between them.
\end{abstract}

Keywords: corruptions perceptions index, GDP, unemployment rate, factor analysis, purchasing power parity.

\section{Introduction}

Corruption Perceptions Index is an indicator of the corruption worldwide calculated that classifies countries according to how corrupt the public sector of the country is. This index is a composite index published since 1995 and represents the perceived level of corruption, determined by expert assessments and opinion polls. It ranks countries on a scale from 0 to 100 , a lower index on this reflects a higher level of corruption, and the higher the index, the lower the level of corruption.

The purpose of the CPI is to provide data on perceived corruption for each country. It consists of credible sources that use different sampling frames and different methodologies. The strength of the CPI is that it is a combination of data, and combined sources in one index increase reliability (Lambsdorff, 2008).

However, there are methodological issues on the reliability and comparability of CPI data. The transnational information are compiled annually using a set of precisely established data sources and trustworthy, but the set used to assess a country and the formulation of questions to experts vary from year to year. Permanent changes lead to a 
difficult estimation of corruption perception. Another factor that leads to a low reliability of an estimate is the large differences in the values given to a country by different sources, and the low number of polls used for a country. Though, the sources and methodologies used are of high quality, so the CPI represents a recognised and widely used index of academics, economists, journalists and business executives.

The results over time show that the countries with the highest scores are developed countries, and those with low scores are less developed. It points out that there is a strong link between the level of economic development of a country and the level of corruption, corruption being an obstacle to sustainable development.

The level of economic development is highlighted by GDP and unemployment rate. This article presents the results of a research that aims to establish a link between the variables describing the level of economic development and the level of corruption at European level for the year 2017. In the first stage the links between the variables are determined, the second stage establishes the relationship between them, highlighting the implications for the development of the economy.

\section{Literature review}

In 2008 Podobnik et al. studied the Corruption Perceptions Index (CPI) in relation to macroeconomic indicators. They analysed CPI, GDP per capita growth rates and foreign direct investments for the period 1999-2004 for all countries in the world. It is noted that the CPI is corelated with the two macroeconomic indicators, between the CPI and the foreign direct investments there is a significant functional dependence, when CPI increase with one unit the annual growth rate of GDP per capita increases by 1.7\% (Podobnik et al., 2008).

Habib and Zurawicki analyse the impact of corruption on foreign direct investment, given that both have a negative impact. They studied the two indicators and the results showed that foreign investments are influenced by the level of corruption, investors avoiding corruption, as it can create operational inefficiencies (Habib and Zurawicki, 2002).

Getz and Volkema studied corruption related to socio-economic factors. The conclusion of the analysis has shown that there is a strong and positive link between economic opposition and corruption, and between corruption and wealth, the link is inversely proportional. Another conclusion is that corruption mediates a negative relationship between economic adversities and wealth, by eliminating uncertainty. The link between economic adversity and corruption is moderated, while the gap between power and avoidance of uncertainty has been positively associated with corruption (Getz and Volkema, 2001).

Robertson and Watson examines how the changes in the level of foreign direct investment (FDI) influence corruption. Using data for two consecutive years, the results indicate that a rapid rate of change in FDI involves a high level of corruption (Robertson and Watson, 2004).

Other studies have focused on the link between corruption and social and cultural factors. Melgar et al. indicate that personal characteristics and social conditions play a relevant role in shaping the perception of corruption. Better economic performance reduces the perception of corruption, macroeconomic instability and income inequality have the opposite effect. At micro level, women, divorced persons, unemployed, employee in the private or self-employed sector are positively correlated with the perception of corruption, and marriage, full-time work, belonging to a religion, and favorable opinion on how 
democracy works in the country have the opposite effect (Melgar et al., 2010).

Davis and Ruhe examines the link between Hofstede's cultural dimensions and how country corruption is perceived. The results show that the variation of perceived corruption is significantly explained by the power of distance, individualism and masculinity and perceived corruption influences significantly country risk, trade flow with other countries, foreign investment and income per capita (Davis and Ruhe, 2003).

\section{Methodology}

The analysis is based on official data published by Eurostat and Transparency International. The data are for the year 2017, registered for 22 countries in the European Union. The variables used in the analysis are:

- Unemployment Rate - Unemployment rate (\%), calculated as a percentage, referring to the country's active population;

- GDP per capita is the medium community GDP, in euro, using purchasing power parity. GDP is reported on the number of inhabitants, it is real, calculated in comparable prices;

- CPI is the perceived level of corruption, measured on a scale from 0 to 100,0 reflects a higher level of corruption, and 100 a lower level of corruption.

The method used was the factor analysis. Principal Component Analysis is a descriptive multidimensional analysis method used to study centered and reduced numeric variables. Principal Component Analysis is a method of factorial analysis that reduces a complex system of variables correlated to a small number of latent variables (Pintilescu, 2007). 2005):

The objectives pursued by an analysis of the principal components are (Baccini,

- the "optimal" graphical representation of individuals, minimizing the deformation of the cloud of points, in a sub-space Eq of dimensions $\mathrm{q}(\mathrm{q}<\mathrm{p})$;

- graphical representation of variables in a sub-space Fq, best explaining the initial links between these variables;

- reduction of size, i.e. approximation of table $X$ through a table $q(q<p)$.

Another method used was the regression analysis. The regression is the existence of a statistic link on the behavior of some variables (Jaba, 2002). In general, any phenomenon is the result of the action of one or more factors. Linear models, variants and extensions are the most useful and used statistical tools for research (Fox, 1997).

Regression analysis is a statistical method by which we study and measure the relationship that exists between two or more variables, as well as the discovery of the relative law in the form of links between variables (Jaba, 2002).

A linear regression model involves identifying the variables, knowing the models used to estimate the parameters of the model, the methods used to test the properties of the regression model estimator and the main aspects of using the regression model in the forecast (Pârțachi et al., 2012 ).

In defining the linear regression function, four hypotheses must be respected:

- the series of data are not affected by registration errors,

- for each fixed value of the factorial characteristic, the residual variable has the mean zero, respectively: $\mathrm{E}\left[\varepsilon_{\mathrm{i}} / \mathrm{X}=\mathrm{xi}=0\right]$, for any $\mathrm{i}$,

- the lack of correlation of residuals expresses the fact that between the residual terms 
there is no covariance phenomenon,

- the hypothesis of the non - correlation of the residual variable with the independent one, which implies that $\operatorname{cov}\left(\mathrm{X}, \varepsilon_{\mathrm{j}}\right)=0$, for any $\mathrm{j}$, showing an increase in the values of the factorial variable that do not automatically lead to an increase in the residual variable values (Anghelache et al., 2014).

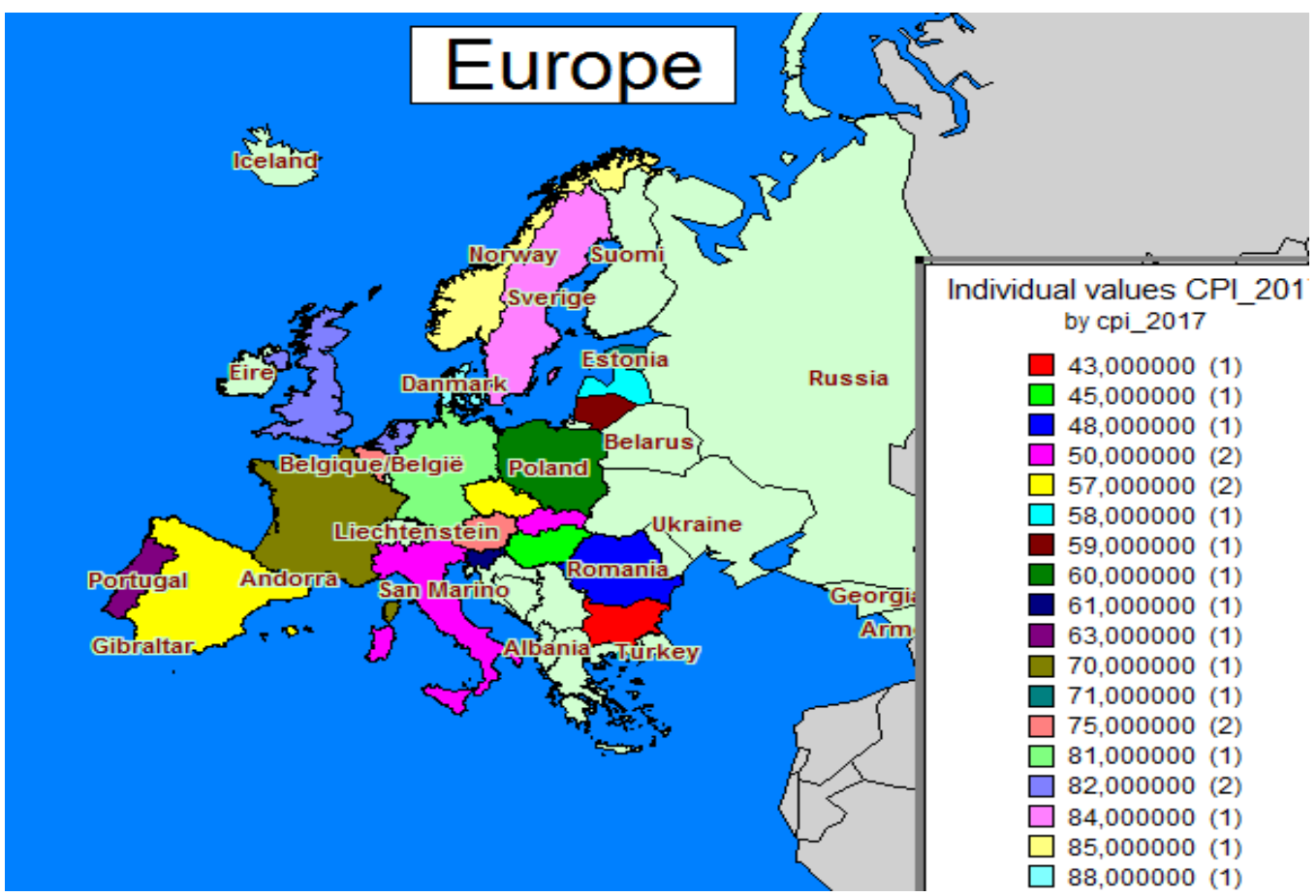

Figure 1. Map of Europefor CPI for 2017

Source: Own projection, usind SPSS

From the graphical representation of the European countries according to the corruption perceptions Index, it is noted that there are no extreme values, the lowest value is slightly less than the half of the scale. These values show that European Index is big, meaning a low level of corruption.

The principal component analysis highlights the correlations between the analysed variables. After data processing in SPSS, the correlation matrix is obtained (Table no. 1). This is a symmetric matrix to the main diagonal and presents the values of the correlation coefficients between variables. The values of the coefficients resulting from the correlation table between variables show that there are statistically significant relationships between the variables considered, so the analysis of the principal components can be applied.

Table 1. Correlation matrix

\begin{tabular}{|l|l|l|l|l|}
\hline & & GDP_capita & Unemployment_rate & CPI 2017 \\
\hline \multirow{3}{*}{ Correlation } & GDP_capita & 1,00 & $-0,08$ & 0,412 \\
\cline { 2 - 5 } & Unemployment_rate & $-0,008$ & 1 & $-0,252$ \\
\cline { 2 - 5 } & CPI 2017 & 0,412 & $-0,252$ & 1 \\
\hline \multirow{3}{*}{ Sig. (1-tailed) } & GDP_capita & & 0,486 & 0,028 \\
\cline { 2 - 5 } & Unemployment_rate & 0,486 & & 0,129 \\
\cline { 2 - 5 } & CPI 2017 & 0,028 & 0,129 & \\
\hline
\end{tabular}

Source: Own projection, usind SPSS 
According to Table 1, the strongest link at European level is between CPI and GDP, and the link is direct and moderate, as GDP increases, the perception index increases, too and the level of corruption decreases. The link between CPI and unemployment rate is weak and inversely, a low unemployment rate generates a high index, and a low level of corruption. This was to be expected because between GDP and unemployment rate the link is inverse.

Table 2. The values of the correlations matrix and the variance explained by the factorial axes

\begin{tabular}{|l|l|l|l|l|l|l|}
\hline \multicolumn{4}{|l|}{ Total Variance Explained } \\
\hline \multirow{2}{*}{ Component } & Initial Eigenvalues & \multicolumn{4}{l|}{ Extraction Sums of Squared Loadings } \\
\cline { 2 - 7 } & Total & $\%$ of Variance & Cumulative \% & Total & \% of Variance & Cumulative \% \\
\hline 1 & 1,486 & 49,547 & 49,547 & 1,486 & 49,547 & 49,547 \\
\hline 2 & 0,993 & 33,106 & 82,653 & 0,993 & 33,106 & 82,653 \\
\hline 3 & 0,520 & 17,347 & 100,00 & & & \\
\hline
\end{tabular}

Source: Own projection, usind SPSS

The values of the correlation matrix correspond to the inertia explained by the factorial axes. For the variables considered, the values are: $\lambda_{1}=1.486, \lambda_{2}=0.993$, and $\lambda_{3}=$ 0.520 . The first factorial axis explains $49.547 \%$ of the total cloud variance. The second factorial axis explains $33.106 \%$, and together with the first axis explains $82.653 \%$ of the total variance.

According to Benzécri's criterion, the number of axes which explains over $70 \%$ of the total variance of the cloud point is chosen, so the first two factorial axes are chosen because together explain the largest differences between the statistical units, respectively 82,653\% of the variance total.

Table 3. Coordinates of the variables on the first two factorial axis

\begin{tabular}{|l|l|l|}
\hline & Component \\
\cline { 2 - 3 } & 1 & 2 \\
\hline GDP_capita & 0,735 & 0,519 \\
\hline Unemployment_rate & $-0,456$ & 0,851 \\
\hline CPI 2017 & 0,859 & 0,007 \\
\hline
\end{tabular}

Source: Own projection, usind SPSS

The coordinates of the variables on the factorial axes show the value of the correlation coefficients between the variables $x_{j}$ and the respective factorial axis (Table no. 3). For example, unemployment rate has a high positive coordinate (0.851) on the second factorial axis and a negative coordinate on the first factorial axis $(-0.456)$. The variable GDP has positive coordinates on both factorial axes, 0.735 on the first factorial axis and 0.519 on the second factorial axis. Since the value is greater for the first component, we conclude that this variable is better explained by the first axis. The case is similar for CPI, it has positive coordinates on both factorial axes, 0.859 on the first factorial axis and 0.007 on the second factorial axis, concluding that this variable is better explained by the first axis.

So, the second factorial axes formed only by variable unemployment rate and the first factorial axes is formed by GDP per capita and CPI.

The graphical representation of the position of CPI, GDP per capita and unemployment rate in the first two axes (Figure no. 2) show a direct link between GDP per capita and CPI, 
because are on both sides of the first factorial axis and an inverse link between them and unemployment rate.

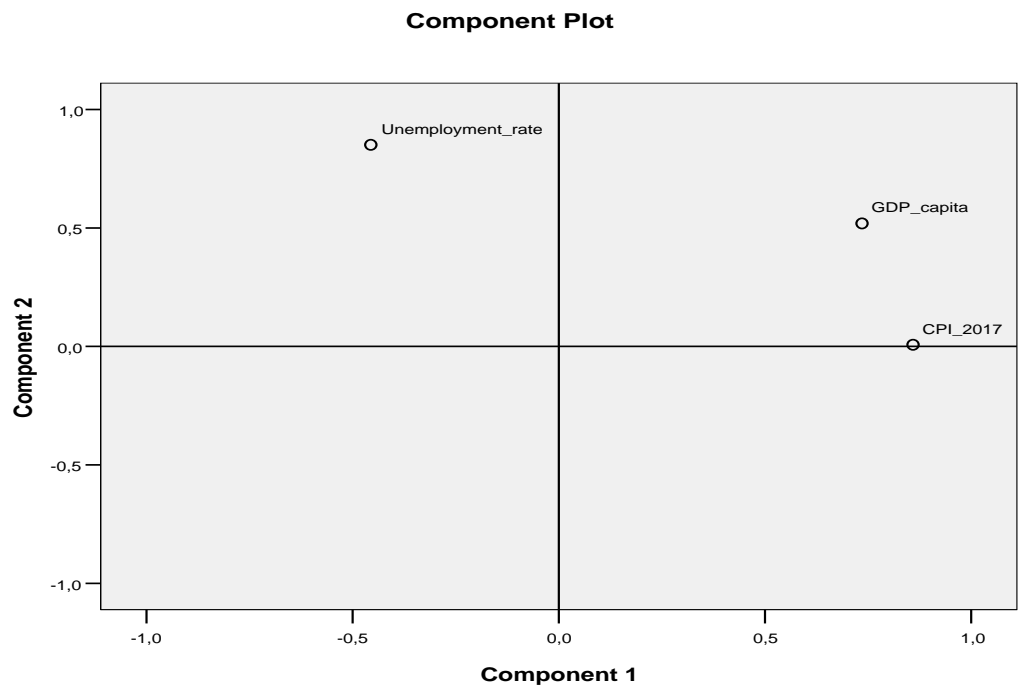

Fiure 2. Representation of variables in the system of the first two factorial axis Source: Own projection, usind SPSS

From countries' graphic representation, high employment rates are recorded in: Italy, France, Latvia, Portugal and Spain. High values for CPI were registered by the countries: Denmark, Sweden, the Netherlands, Estonia and the United Kingdom. The country with the largest GDP is Sweden.

Graph

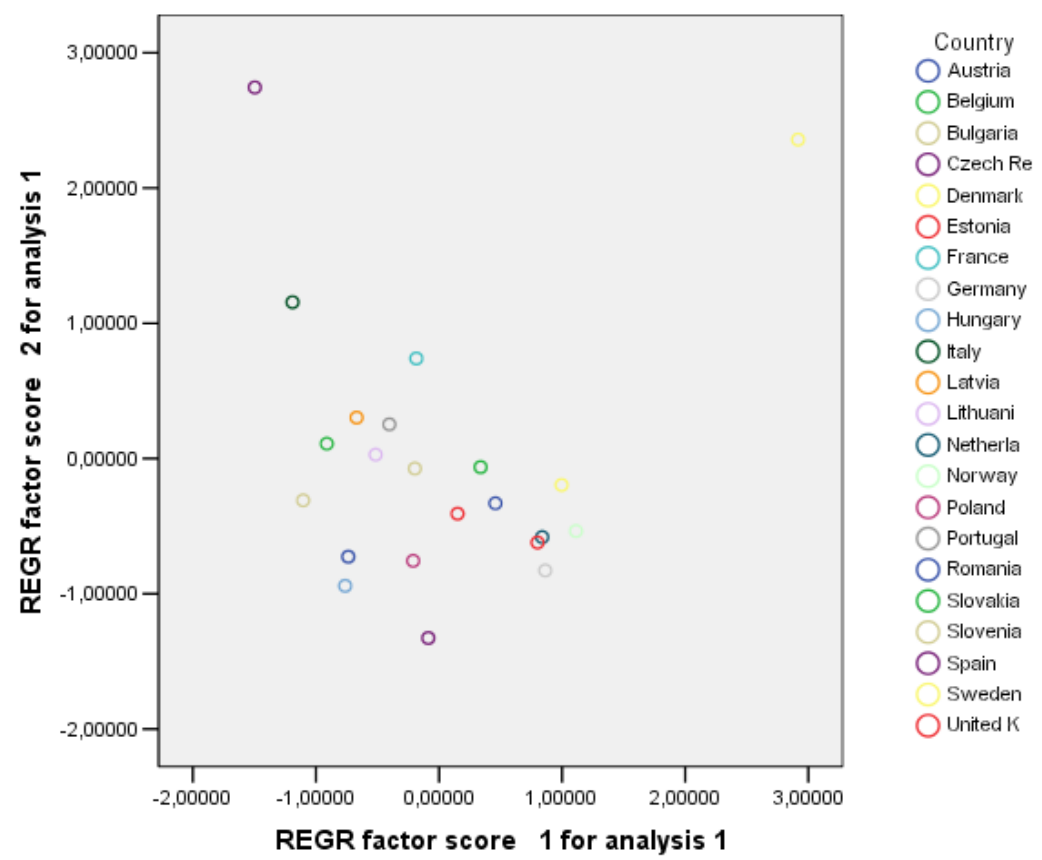

Figure 3. Representation of the countries in the system of the first two factorial axis Source: Own projection, usind SPSS 
Table 4. Model Summary

\begin{tabular}{|l|ll|l|l|l|}
\hline Model & & $\mathrm{R}$ & R Square & Adjusted R Square & Std. Error of the estimate \\
\hline 1 & 0,481 & 0,232 & 0,151 & 13,12 \\
\hline \multicolumn{5}{|r}{} \\
\cline { 2 - 4 }
\end{tabular}

Table 4 shows that the variance of the corruption index is influenced in percent of $48,1 \%$ by unemployment rate and GDP per capita, and the link between them is weak.

Table 5. Model validity (ANOVA)

\begin{tabular}{|l|l|l|l|l|l|l|}
\hline \multicolumn{2}{|l|}{ Model } & Sum of Squares & df & Mean Square & F & Sig \\
\hline \multirow{3}{*}{1} & Regression & 986,32 & 2 & 493,16 & 2,865 & 0,082 \\
\cline { 2 - 8 } & Residual & 3270,76 & 19 & 172,15 & & \\
\cline { 2 - 8 } & Total & 4257,09 & 21 & \multicolumn{3}{|c|}{ Source: Own projection, usind SPSS }
\end{tabular}

Applying the regression analysis, it is observed that the model is valid (Table 5) and the coefficient GDP per capita is significant and the coefficient unemployment rate is not significant for EU for 2017 (Table 6). So, much more important for the perception of corruption is the standard of living, expresed by GDP, than unemployment rate.

Table 6. Coefficients significance

\begin{tabular}{|l|l|l|l|l|l|l|}
\hline \multicolumn{2}{|l|}{ Model } & \multicolumn{2}{|l|}{ Unstandardized Coefficients } & Standardized Coefficients & t & Sig \\
\cline { 3 - 8 } \multicolumn{2}{|l|}{1} & B Std. Error & Beta & & \\
\hline \multirow{3}{*}{1} & Constant & 70,26 & 6,85 & & 10,255 & 0 \\
\cline { 2 - 7 } & GDP_capita & $5,32 \mathrm{E}-05$ & 0 & 0,41 & 2,041 & 0,055 \\
\cline { 2 - 7 } & Unemployment_rate & $-1,181$ & 0,956 & $-0,248$ & $-1,235$ & 0,232 \\
\hline
\end{tabular}

Source: Own projection, usind SPSS

From Table 6 can be concluded that when GDP grows with one unit, the corruption perception index increases by $5,32^{*} 10^{-5}$, so a high GDP implies a high level of the index, which means a low level of corruption.

\section{Conclusion}

This paper follows to establish the link between some important macroeconomic indicators and the corruption perception index for Europe in the 2017 and tries to find out which variables affect this index. A factor analysis was used in 22 countries from Europe.

The strongest link for Europe is between GDP and CPI, and the link is direct. Between unemployment rate and $\mathrm{CPI}$ is an inverse link, the lower the CPI, the higher the unemployment rate. Between GDP and unemployment rate the link is inverse, as is in the economic theory, when GDP increases, the unemployment rate decreases.

It can be concluded that the corruption perception index for Europe is explained by the GDP per capita, so for Europe the economic situation of a country influences CPI significantly.

Further research aims to extend the sample globally, but also to include other variables. In addition, depending on the possibilities of accessing the specific data series, the study can also be applied for the Romanian regions. 


\section{References}

Baccini, A., Besse, P.: Data mining I Exploration Statistique. Universite Paul Sabatie Press, Toulouse (2005).

Fox, J.: Applied regression analysis, linear models, and related methods. CA. Sage Publications, Thousand Oaks (1997).

Getz, K.A. and Volkema, R.J.: Culture, Perceived Corruption, and Economics A Model of Predictors and Outcomes. Business \& Society, 40(1), pp. 7-30 (2001).

Habib, M. and Zurawicki, L.: Corruption and Foreign Direct Investment. Journal of International Business Studies, 33 (2), pp. 291-307 (2002).

Jaba, E.: Statistica, 2nd Edition. Editura Economică, Bucureşti (2002).

Lambsdorff, J.G.: The Methodology of the Corruption Perceptions Index. Transparency International (TI) and University of Passau (2006).

Melgar, N., Rossi, M., Smith, T.W.: The Perception of Corruption. International Journal of Public Opinion Research, 22(1), pp.120-131 (2010).

Pârțachi, I., Diaconu, A., Dinu, A. M., Păunescu, C.: Noţiuni generale privind regresia liniară simplă. Revista de Statistică, Supliment 3,128-132 (2012).

Pintilescu, C.: Multivariate statistic analysis. The University “Al. I Cuza” Pres, Iasi (2007).

Podobnik, B., Shao, J., Njavro, D., Ivanov, P.C., Stanley, H.E.: Influence of corruption on economic growth rate and foreign investment. The European Physical Journal B, 63(4), pp. 547-550 (2008).

Robertson, C.J. and Watson, A.: Corruption and change: the impact of foreign direct investment. Strategic Management Journal, 25(4), pp. 385-396 (2004). 